\title{
List of Abbreviations and References
}

\author{
$A B V$ \\ Beazley, J.D. 1956. Attic Black-Figure Vase-Painters (Oxford) \\ $A N R W$ \\ Temporini, H. and Haase, W. (eds.) 1972-. Aufstieg und Niedergang der \\ römischen Welt (Berlin - New York) \\ $A R V$ \\ $A R V^{2}$ \\ Beazley, J.D. 1942. Attic Red-figure Vase-painters (Oxford) \\ Ausf.Lexicon \\ Beazley, J.D. ${ }^{2}$ 1963. Attic Red-figure Vase-painters (Oxford)

$B A P D$ \\ Roscher, W.H. (ed.) 1884-1937 Ausführliches Lexicon der griechischen und \\ römischen Mythologie, 7 vols. (Leipzig) \\ CIL \\ CVA \\ Didyma \\ DNP \\ Beazley Archive Pottery Database (Oxford) (www.beazley.ox.ac.uk/pottery/ \\ default.htm) \\ Corpus Inscriptionum Latinarum, 1863 - (Berlin) \\ Corpus Vasorum Antiquorum, 1925- \\ Rehm, A. 1958. Didyma, Vol. II: Die Inschriften (hrsg. von Harder, R.) (Berlin) \\ Cancik, H., Schneider, H. and Landfester, M. (eds.) 1996-2003. Der Neue \\ Pauly, 19 vols. (Stuttgart) \\ F.Delphes \\ FGrH \\ FIRA \\ Fouilles de Delphes, 1902- (Paris) \\ Jacoby, F. 1923- . Die Fragmente der griechischen Historiker (Berlin/Leiden) \\ Riccobono, S. et al. (eds.) 1940-1943. Fontes luris Romani Antelustiniani, \\ 3 vols. (Florence) \\ I.Magnesia Kern, O.1900. Die Inschriften von Magnesia am Maeander (Berlin) \\ I.Stratonikeia Şahin, M.Ç. 1981-1990. Die Inschriften von Stratonikeia, Vols. I-II 1/2 (Bonn) \\ I.Thespiai Roesch, P. 2009. Les inscriptions de Thespies (édition électronique mise en \\ forme par Argoud, G., Schachter, A. and Vottéro, G.) (Lyon) \\ IG \\ IGSK \\ Inscriptiones Graecae, 1873- (Berlin) \\ Inschriften griechischer Städte aus Kleinasien, 1972- (Bonn) \\ IGUR \\ ILS \\ Moretti, L., 1968-1979. Inscriptiones Graecae Urbis Romae (Rome) \\ Dessau, H. 1892-1916. Inscriptiones Latinae Selectae, 3 vols. (Berlin) \\ K-A \\ Kassel, R. and Austin, C. 1983-2001. Poetae Comici Graeci, 8 vols. \\ (Berlin - New York) \\ K-G Kühner, R. and Gerth, B. 1898-1904. Ausführliche Grammatik der \\ griechischen Sprache, 2 vols. (Hannover) \\ LBW Le Bas, P. and Waddington, W.H., 1870. Voyage archéologique en Grèce et en \\ Asie Mineure: Inscriptions grecques et latines recueillies en Grèce et en Asie \\ Mineure, Vol. III (Paris) \\ LDAB Leuven Database of Ancient Books (www.trismegistos.org/ldab) \\ LGPN Fraser, P.M. and Matthews, E. (eds.) 1987- . A Lexicon of Greek Personal \\ Names (Oxford) \\ LIMC Lexicon Iconographicum Mythologiae Classicae, 1981- (Zürich) \\ LSJ Liddell, H.G., Scott, R., Jones, H.S. and McKenzie, R. (eds.) ${ }^{9} 1996$. A Greek- \\ English Lexicon (with a revised supplement by Glare, P.G.W. and Thompson, \\ A.A.) (Oxford) \\ Monlst Monumenti inediti pubblicati dall'istituto di corrispondenza archeologica - \\ Monuments inédits publiés par l'institute de correspondance archéologique \\ (Rome)
}




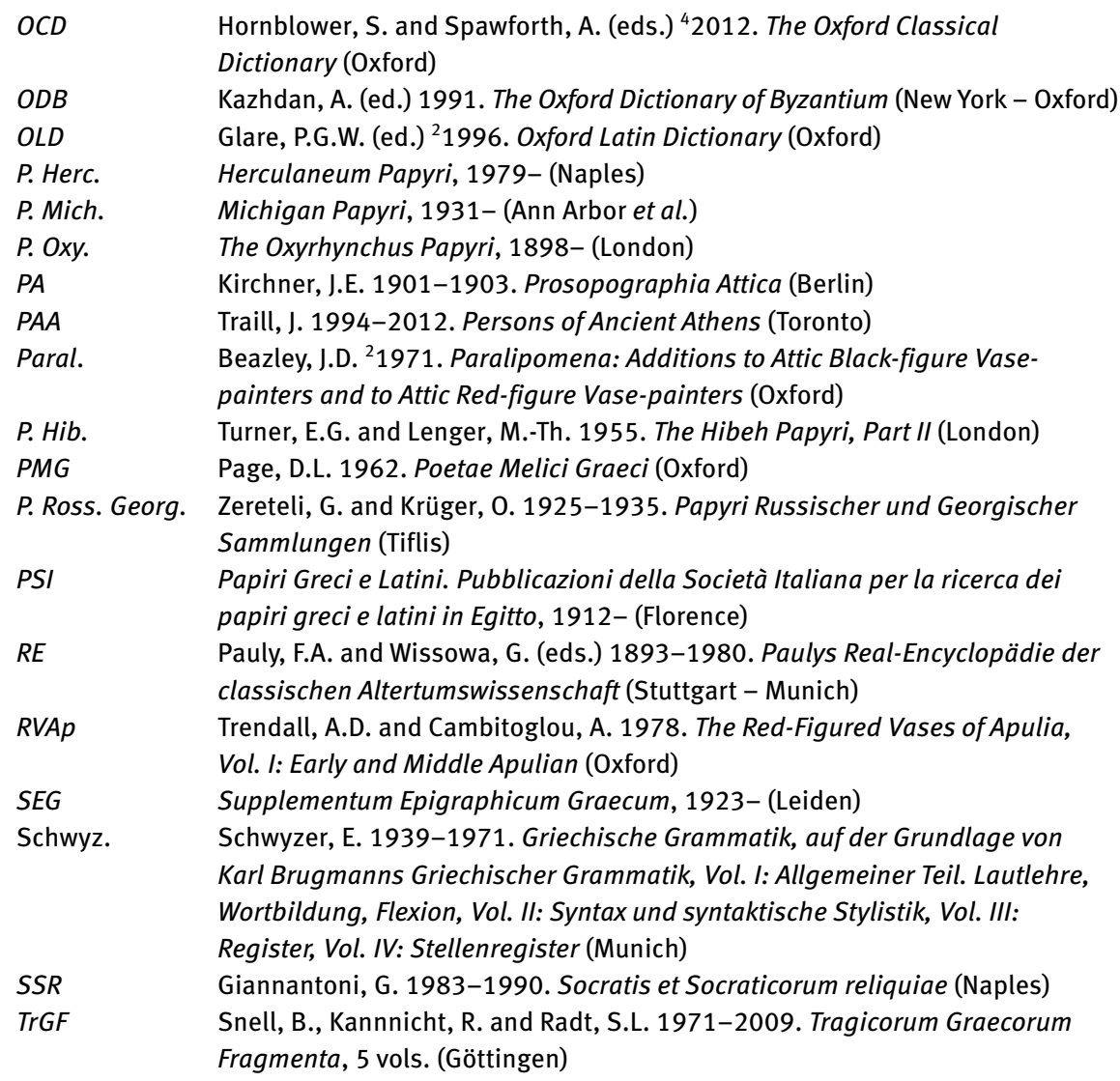

Note: For abbreviations of periodicals refer to the list of L'Année philologique on the Internet (www.anneephilologique.com/files/sigles_fr.pdf)

\section{References to Fragments}

Unless otherwise stated, dramatic fragments are cited in the following editions:

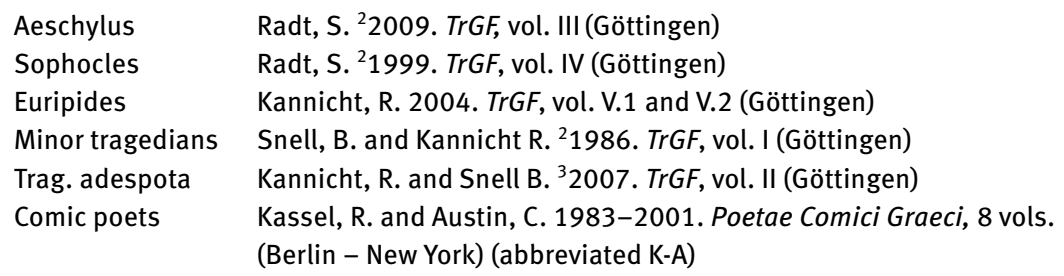

All other fragments are cited by name of their respective editor. 